\title{
latrogenic adrenal insufficiency as a side-effect of combined treatment of itraconazole and budesonide
}

\author{
M. Skov*, K.M. Main\#, I.B. Sillesen", J. Müller\#, C. Koch*, S. Lanng*
}

Iatrogenic adrenal insufficiency as a side-effect of combined treatment of itraconazole and budesonide. M. Skov, K.M. Main, I.B. Sillesen, J.Müller, C. Koch, S. Lanng. (C) ERS Journals Ltd 2002.

ABSTRACT: A recent case of iatrogenic Cushing's syndrome and complete suppression of the pituitary-adrenal-axis in a patient with cystic fibrosis (CF) and allergic bronchopulmonary aspergillosis treated with itraconazole as an antifungal agent, and budesonide as an anti-inflammatory agent led to a systematic assessment of this axis and gonadal function in all patients treated with itraconazole in the authors' CF centre. Itraconazole can inhibit CYP3A, thus interfering with synthesis of glucoand mineralocorticoids, androgens and oestradiol as well as the metabolism of budesonide. The aim of this study was to evaluate adrenal and gonadal function in patients treated with itraconazole with or without budesonide.

An adrenocorticotrophic hormone (ACTH) test $(250 \mu \mathrm{g}$ tetracosactid) was performed in $25 \mathrm{CF}$ patients treated with both itraconazole and budesonide, and in 12 patients treated with itraconazole alone (six patients with $C F$ and six with chronic granulomateous disease). Mineralocorticoid and gonadal steroid function were evaluated by measurements of plasma-renin, follicle stimulating hormone, luteinising hormone, progesterone, oestradiol, testosterone, serum-inhibin A and B. ACTH tests performed as part of a pretransplantation programme in an additional $30 \mathrm{CF}$ patients were used as controls.

Eleven of the 25 patients treated with both itraconazole and budesonide had adrenal insufficiency. None of the patients on itraconazole therapy alone nor the control $\mathbf{C F}$ patients had a pathological ACTH test. Mineralocorticoid and gonadal insufficiency was not observed in any of the patients. Only one patient with an initial pathological ACTH-test subsequently normalised, the other 10 patients improved but had not achieved normalised adrenal function 2-10 months after itraconazole treatment had been discontinued.

Suppression of the adrenal glucocorticoid synthesis was observed in 11 of 25 cystic fibrosis patients treated with both itraconazole and budesonide. The pathogenesis is most likely an itraconazole caused increase in systemic budesonide concentration through a reduced/inhibited metabolism leading to inhibition of adrenocorticotrophic hormone secretion along with a direct inhibition of steroidogenesis. In patients treated with this combination, screening for adrenal insufficiency at regular intervals is suggested.

Eur Respir J 2002; 20: 127-133.
*Cystic Fibrosis Centre, "Dept of Growth and Reproduction, National University Hospital, Rigshospitalet, Copenhagen and "Clinical Pharmacological Unit, Gentofte Hospital, Denmark.

Correspondence: M. Skov CF-Centre 5003

National University Hospital

Rigshospitalet

Blegdamsvej 9

DK-2100 Copenhagen

Denmark

Fax: 4535456412

E-mail: mskov@dadlnet.dk

Keywords: Adrenal insufficiency allergic bronchopulmonary aspergillosis budesonide

CYP3A

cystic fibrosis

itraconazole

Received: May 292001

Accepted after revision: January 17 2002
Allergic bronchopulmonary aspergillosis (ABPA) is characterised by a dual-type immune response with immunoglobulin ( $\mathrm{Ig}$ ) $\mathrm{E}$ and $\mathrm{IgG}$ antibodies to the fungus Aspergillus fumigatus [1]. It is diagnosed in $\sim 8 \%$ of cystic fibrosis (CF) patients and in $1-2 \%$ of patients with bronchial asthma [2-4]. The mainstay of treatment for ABPA in $\mathrm{CF}$, as in patients with bronchial asthma, has been systemic glucocorticoids, but this is associated with serious side-effects particularly in growing children [5-7]. Treatment with itraconazole, an orally administered triazole antifungal agent, has recently been recommended for the treatment of ABPA as an efficient alternative or steroidsparing therapy without serious side-effects [8-10]. Itraconazole is, like other antibiotics, administered in high doses in $\mathrm{CF}$ patients due to the endobronchial barrier and altered pharmocokinetics, especially with regard to the increased renal excretion [11]. Budesonide is given as an anti-inflammatory agent in many $\mathrm{CF}$ centres [12, 13]. High-dose budesonide was primarily recommended to $\mathrm{CF}$ patients chronically infected with Pseudomonas aeruginosa [14], but has since been extended to include CF patients with other bacterial infections. Azoles such as ketoconazole and itraconazole are strong inhibitors of cytochrome P450 dependent CYP3A4, which is involved in the metabolism of budesonide [15-17]. Ketoconazole has an inhibitory effect on other cytochrome P450-dependent enzymes such as 17,20 desmolase, 16 $\alpha$-hydroxylase, $17 \alpha$-hydroxylase, 18 hydroxylase and $11 \beta$-hydroxylase 
enzymes (listed with decreasing activity), thus potentially compromising steroidogenesis in the adrenals and gonads [18, 19]. Budesonide is metabolised to 16- $\alpha$-hydroxyprednisolone and 6- $\beta$-hydroxybudesonide by hepatic CYP3A [15], and the metabolism is therefore reduced in individuals taking drugs that inhibit CYP3A.

The frequency of suppression of the pituitaryadrenal-axis and gonadal steroidogenesis due to pharmacological interaction of itraconazole and budesonide was prospectively studied in a group of 31 patients with $\mathrm{CF}$ and six patients with chronic granulomateous disease (CGD) and compared to a control group of $30 \mathrm{CF}$ patients who had been tested as part of a pretransplantation programme.

\section{Patients and methods}

\section{Patients}

All CF patients $(n=31)$ from the Danish CF Centre, Copenhagen, who were treated with itraconazole for ABPA agreed to participate in the study. Up until the end of 199931 patients (16 females, 15 males, median age 18 yrs (range 9-33 yrs)) of a total of 271 patients $(11 \%)$ were treated with high-dose itraconazole $\left(400-600 \mathrm{mg} \cdot \mathrm{day}^{-1}, 10 \mathrm{mg} \cdot \mathrm{kg}^{-1} \cdot \mathrm{day}^{-1}\right)$. Five patients were also treated with prednisolone and four patients with clarithromycin. Eight of the females aged $>15$ yrs used oral contraception and three females did not. Of the five female patients aged $<15$ yrs one was Tanner stage of puberty 4 , two were stage $4-5$, one was stage 5 and in one patient the stage was unknown.

Group 1: Twenty-five patients were treated, concomitantly with high-dose budesonide inhalations (Spirocort Turbohaler®, AstraZeneca, Albertslund, Denmark) (800-1600 $\mu \mathrm{g}$ day, median age $18 \mathrm{yrs}$ (range 9-33 yrs)) and itraconazole. Group 2: Six patients were treated with itraconazole alone. Group 3: Six patients with CGD who were on continuous prophylactic treatment with high-dose itraconazole for ABPA (two females, four males), median age 24 yrs (range 15-32 yrs). None of these patients were or had been treated with budesonide or clarithromycin. Group 4: The adrenocorticotropic hormone (ACTH) test results from a group of $30 \mathrm{CF}$ patients were retrospectively included as controls (14 females, 16 males), median age 29 yrs (range $21-43$ yrs). An ACTH test had been performed as part of a preoperative evaluation for lung transplantation. None of these patients were treated with itraconazole but 24 of them had been treated for several years with high-dose inhaled budesonide. The remaining six were not treated with glucocorticosteroids.

\section{Follow-up}

Patients with pathological ACTH test results, not treated with prednisolone, started with hydrocortisone substitution therapy $\left(10-12 \mathrm{mg} \cdot \mathrm{m}^{-2} \cdot \mathrm{day}^{-1}\right)$ after withdrawal of itraconazole. The budesonide treatment was slowly withdrawn if the patients did not experience a deterioration in asthmatic symptoms. After withdrawal of itraconazole the adrenal function was retested with ACTH tests at intervals of 1-3 months.

\section{Methods}

Measurements of glucocorticoids and mineralocorticoids. Adrenocorticotropic hormone test. Plasma cortisol was measured before (time 0), 30 and $60 \mathrm{~min}$ after intravenous (i.v.) injection of $250 \mu \mathrm{g}$

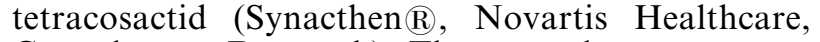
Copenhagen, Denmark). The normal response was defined as an increase of plasma cortisol to at least $500 \mathrm{nmol} \cdot \mathrm{L}^{-1}$ after $60 \mathrm{~min}$ (AutoDelfia, Wallac, Finland). Patients treated with prednisolone at the time of testing did not take the medication on the test day. In these patients cortisol was measured using high-performance liquid chromatography (Merck, Hitachi, Japan), a method in which crossreactivity between cortisol and prednisolone is avoided.

Plasma adrenocorticotropic hormone. Plasma ACTH was measured at time 0 (normal range $2-11 \mathrm{pmol} \cdot \mathrm{L}^{-1}$ ) using a radioimmunoassay (RIA) (Nichols Inst., Diagnostics, CA, USA).

Plasma renin. Plasma renin concentration was determined using the principle of antibody trapping [20] as modified by MiLler et al. [21] (normal range 6-60 $\mathrm{mIU} \cdot \mathrm{L}$ ) after $30 \mathrm{~min}$ rest in the supine position.

Measurements of gonadal hormones. Sex-hormone analyses (at time 0): plasma follicle stimulating hormone (detection limit $0.05 \mathrm{IU} \cdot \mathrm{L}^{-1}$ ), luteinizing hormone (detection limit $0.06 \mathrm{IU} \cdot \mathrm{L}^{-1}$ ) and progesterone concentration (detection limit $0.8 \mathrm{nmol} \cdot \mathrm{L}^{-1}$ ) were measured by a time-resolved immunofluorometric assay (Delfia, Wallac, Finland).

Testosterone concentration (detection limit $0.23 \mathrm{nmol}$ $\mathrm{L}^{-1}$ ) was determined by RIA (Coat-a-Count; Diagnostic Products Corporation, LA, USA). Oestradiol concentration (detection limit $18 \mathrm{pmol} \cdot \mathrm{L}^{-1}$ ) was also determined by RIA (Immunodiagnostic Systems, Boldon, UK). Inhibin-A (detection limit $7 \mathrm{pg} \cdot \mathrm{mL}^{-1}$ ) [22] and inhibin-B concentrations (detection limit $18 \mathrm{pmol} \cdot \mathrm{L}^{-1}$ ) [23] were determined by enzyme-linked radioimmunosorbant assay (ELISA).

\section{Statistics}

Statistical analysis was performed using the nonparametric Mann-Whitney U-test for comparison between two groups. For comparison between more than two groups the nonparametric Kruskall-Wallis test was used. A $\mathrm{p}<0.05$ was considered significant.

\section{Ethics}

Ethical approval was obtained ((KF) 01-046/00) and the study was performed according to the Helsinki II declaration. 


\section{Results}

\section{Glucocorticoid and mineralocorticoid function}

A pathologically low response to the ACTH test was found in 11 of 25 (44\%) CF patients treated with itraconazole and budesonide (Group 1a) (table 1). Plasma ACTH was low in eight of the 11 patients, normal in two patients and in one patient plasma ACTH was not measured initially but a subsequent analysis was normal (table 1). Some patients were treated with prednisolone or claritromycin (table 1). One patient developed Cushing's syndrome with moon face, striae, facial hair growth, headache, mood swings, increased insulin requirement, dysregulation of diabetes, high HbAlc and irregular menstruations (table 1, patient no. 3).

A normal response to the ACTH test was found in the remaining $14 \mathrm{CF}$ patients treated with itraconazole and budesonide (Group 1b) and the six CF patients treated with itraconazole alone (Group 2) (fig. 1). Two patients were treated with clarithromycin

Table 1.-Details of 11 patients with cystic fibrosis and allergic bronchopulmonary aspergillosis showing a pathological adrenocorticotropic hormone test

\begin{tabular}{|c|c|c|c|c|c|c|c|c|c|}
\hline \multirow[t]{2}{*}{ Patient no. } & \multirow[t]{2}{*}{ Age yrs } & \multicolumn{3}{|c|}{ Itraconazole treatment } & \multirow{2}{*}{$\begin{array}{l}\text { Time } \\
\text { months }\end{array}$} & \multirow{2}{*}{$\begin{array}{l}\text { p-ACTH } \\
\mathrm{pmol} \cdot \mathrm{L}^{-1 \#}\end{array}$} & \multicolumn{3}{|c|}{$\mathrm{p}$-cortisol $\mathrm{nmol} \cdot \mathrm{L}^{-1}$} \\
\hline & & $\begin{array}{l}\text { Median dose } \\
\mathrm{mg} \cdot \text { day }^{-1}\end{array}$ & $\begin{array}{c}\text { Duration } \\
\text { months }\end{array}$ & $\begin{array}{l}\text { Accumulated } \\
\text { dose g }\end{array}$ & & & $0 \mathrm{~min}$ & $30 \mathrm{~min}$ & $60 \mathrm{~min}$ \\
\hline \multirow[t]{4}{*}{1} & \multirow[t]{4}{*}{24} & \multirow{4}{*}{400} & \multirow[t]{4}{*}{4} & \multirow{4}{*}{48} & 0 & $<1$ & $<15$ & 47 & 16 \\
\hline & & & & & 3 & 1 & 20 & 55 & 66 \\
\hline & & & & & 6 & 6 & 43 & 71 & 86 \\
\hline & & & & & 9 & 10 & 39 & 63 & 55 \\
\hline \multirow[t]{2}{*}{$2^{\top}$} & \multirow[t]{2}{*}{21} & \multirow[t]{2}{*}{300} & \multirow[t]{2}{*}{100} & \multirow[t]{2}{*}{669} & 0 & $<1$ & $<30$ & 143 & 183 \\
\hline & & & & & 2 & 1 & 152 & 367 & 459 \\
\hline \multirow[t]{5}{*}{$3^{+}$} & \multirow[t]{5}{*}{20} & \multirow[t]{5}{*}{200} & \multirow[t]{5}{*}{77} & \multirow[t]{5}{*}{635} & 0 & $<1$ & $<15$ & $<15$ & $<15$ \\
\hline & & & & & 4 & 4 & 189 & 320 & 367 \\
\hline & & & & & 5 & 8 & 170 & 290 & 321 \\
\hline & & & & & 8 & & 59 & 222 & 239 \\
\hline & & & & & 10 & & $<30$ & 140 & 155 \\
\hline \multirow{5}{*}{$4^{+}$} & \multirow{5}{*}{19} & 500 & 48 & 768 & 0 & & $<15$ & $<15$ & $<15$ \\
\hline & & & & & 1 & 4 & 266 & 280 & 372 \\
\hline & & & & & 2 & 7 & 223 & 313 & 310 \\
\hline & & & & & 5 & 19 & 305 & 366 & 382 \\
\hline & & & & & 7 & & 191 & 208 & 213 \\
\hline 5 & 18 & 200 & 96 & 678 & 0 & $<1$ & $<15$ & 71 & 122 \\
\hline & & & & & 3 & 2 & 114 & 186 & 229 \\
\hline & & & & & 6 & & 153 & 218 & 243 \\
\hline & & & & & 10 & & 163 & 292 & 324 \\
\hline 6 & & 300 & 38 & 264 & 0 & 1 & $<15$ & $<15$ & $<15$ \\
\hline & & & & & 2 & & 37 & 28 & 25 \\
\hline & & & & & 3 & 3 & $<15$ & $<15$ & $<15$ \\
\hline & & & & & 5 & 1 & $<15$ & $<15$ & $<15$ \\
\hline & & & & & 9 & & 85 & 112 & 123 \\
\hline $7^{\S}$ & 9 & 100 & 1 & 3 & 0 & $<1$ & $<15$ & $<15$ & 25 \\
\hline 8 & 13 & 600 & 3 & 54 & 0 & & $<15$ & 36 & 55 \\
\hline & & & & & 3 & 1 & 12 & 181 & 220 \\
\hline & & & & & 6 & & 259 & 324 & 372 \\
\hline & & & & & 9 & & 233 & 314 & 352 \\
\hline 9 & 20 & 400 & 55 & 788 & 0 & 3 & 103 & 285 & 348 \\
\hline & & & & & 2 & 3 & 190 & 277 & 368 \\
\hline & & & & & 7 & 6 & 271 & 453 & 521 \\
\hline 10 & 15 & 200 & 75 & 420 & 0 & 7 & 60 & 342 & 405 \\
\hline & & & & & 2 & 11 & 208 & 362 & 438 \\
\hline & & & & & 3 & 4 & 63 & 286 & 340 \\
\hline & & & & & 6 & 13 & 239 & 401 & 439 \\
\hline $11^{f}$ & 13 & 100 & 57 & 255 & 0 & $<1$ & & & \\
\hline & & & & & 1 & 1 & $<30$ & 57 & 81 \\
\hline & & & & & 7 & & 61 & 82 & 80 \\
\hline
\end{tabular}

The daily dose, accumulated dose and duration of itraconazole treatment, results of plasma-adrenocorticotropic ( $\mathrm{p}-\mathrm{ACTH})$ and spontaneous and stimulated plasma-cortisol p-cortisol measurements after 30 and 60 min are shown. All patients were treated with budesonide. Itraconazole treatment was withdrawn at time $=0$. $\mathrm{p}$-ACTH and p-cortisol were measured during the following period (given as number of months after time $=0$ ). ${ }^{\#}$ : p-ACTH normal range $2-10 \mathrm{pmol} \cdot \mathrm{L}^{-1}$; ${ }^{\top}$ : patient receiving concomitant treatment with prednisolone $\left(10 \mathrm{mg} \cdot 2 \mathrm{nd} \mathrm{day}^{-1}\right){ }^{+}:$: clanthromycin $\left(500 \mathrm{mg} \cdot \mathrm{day}^{-1}\right){ }^{\text {s }}{ }^{\text {: }}$ prednisolone $\left(30 \mathrm{mg} \cdot \mathrm{day}^{-1}\right)$; $f:$ prednisolone $\left(7.5 \mathrm{mg} \cdot 2 \mathrm{nd} \mathrm{day}^{-1}\right)$. 


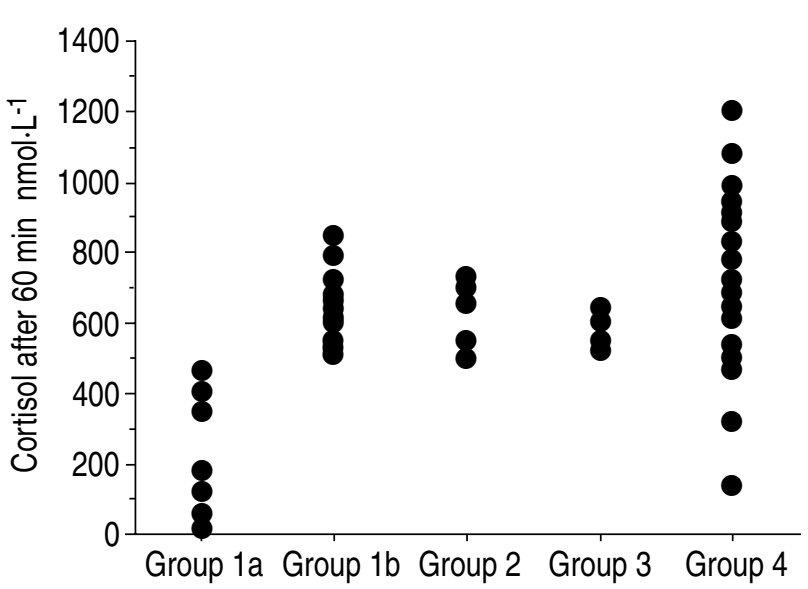

Fig. 1.-Maximal plasma-cortisol levels $60 \mathrm{~min}$ after stimulation with tetracosactid $(250 \mu \mathrm{g})$ in patients treated with budesonide and itraconazole with a low response to the adrenocorticotropic hormone test (Group 1a, n=11), patients treated with budesonide and itraconazole with a normal response to the adrenocorticotropic hormone test (Group 1b, $n=14$ ), patients treated with itraconazole alone (Group 2, $\mathrm{n}=6$ ), patients with chronic granulomateous disease treated with itraconazole (Group 3, $\mathrm{n}=6$ ), and controls (Group 4, $\mathrm{n}=30$ ). The minimal level of a normal response is $500 \mathrm{nmol} \cdot \mathrm{L}^{-1}$. Two patients in Group 4 had levels $<500 \mathrm{nmol} \cdot \mathrm{L}^{-1}$ due to administration of prednisolone at time of testing.

and two other patients with prednisolone. The plasma-ACTH levels were within the normal range (fig. 2).

The accumulated itraconazole dose in CF patients with a pathologically low response to the ACTH test was not significantly different from the accumulated itraconazole dose in $\mathrm{CF}$ patients with a normal response to the ACTH test (median $420 \mathrm{~g}$ (range 3-788 g) versus $453 \mathrm{~g}$ (range 4.8-1047 g) ( $\mathrm{p}=0.95)$.

All six CGD patients (Group 3) treated with itraconazole alone had a normal reponse to the ACTH test (fig. 1) as well as a plasma ACTH within the normal range (fig. 2). The plasma ACTH values

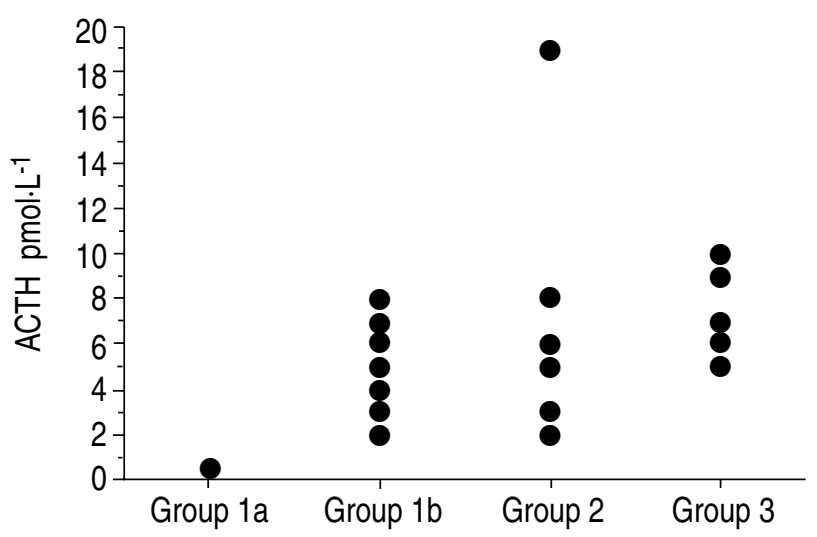

Fig. 2.-Plasma-adrenocorticotropic (ACTH) levels in patients treated with budesonide and itraconazole with a low response to the ACTH test (Group 1a, n=11), patients treated with budesonide and itraconazole with a normal response to the ACTH test (Group 1b, n=14), patients treated with itraconazole alone (Group $2, n=6)$, patients with chronic granulomateous disease treated with itraconazole (Group 3, $n=6$ ). were not statistically different within the different groups $(\mathrm{p}=0.1)$.

Twenty-four of the $30 \mathrm{CF}$ patients in the control group treated with high-dose budesonide alone (Group 4), had a normal response to the ACTH test (fig. 1). Plasma-ACTH was not measured in these patients.

Mineralocorticoid insufficiency was not observed in any of the $31 \mathrm{CF}$ patients treated with itraconazole as indicated by normal plasma-renin concentrations (Group 1a: median 21, range 7-84 $\mathrm{mIU} \cdot \mathrm{L}^{-1}$; Group 1b: median 18, range 5-46 $\mathrm{mIU} \cdot \mathrm{L}^{-1}$; Group 2: median 14, range 4-53 $\mathrm{mIU} \cdot \mathrm{L}^{-1}$; Group 3: median 21 , range 11-107 $\left.\mathrm{mIU} \cdot \mathrm{L}^{-1}\right)$. The renin values were not statistically different within the groups $(p=0.9)$. Renin measurements were not performed in Group 4.

\section{Gonadal function}

Suppression of sex-hormone secretion was not observed in any of the $31 \mathrm{CF}$ patients or the six CGD patients treated with itraconazole. In one male CF patient a high follicle stimulating hormone (FSH) $\left(24.9 \mathrm{nmol} \cdot \mathrm{L}^{-1}\right)$ and low serum-inhibin B $\left(<20 \mathrm{pg} \cdot \mathrm{mL}^{-1}\right)$ level were observed indicating lack of Sertoli cell function unrelated to the current investigation and the disease being studied.

\section{Follow-up}

Most of the patients with an initial pathological ACTH test improved, but the adrenal function did not normalise after a follow-up of $2-10$ months (table 1 ). In six patients the tetracosactid-stimulated plasma cortisol level increased after withdrawal of itraconazole to levels of $\sim 250-400 \mathrm{nmol} \cdot \mathrm{L}^{-1}$. The subsequent tests showed only a slow further improvement in adrenal function. Substitution with hydrocortisone at a standard dose resulted in symptoms of Cushing's syndrome, consisting of moon face and deterioration in glucose tolerance, in two patients.

After withdrawal of itraconazole treatment, all the patients were closely controlled with specific IgG subclass antibodies to A. fumigatus [24] in order to follow the activity of ABPA. In patients with increasing specific IgG subclass antibodies and clinical signs of exacerbation in ABPA, itraconazole treatment was restarted after withdrawal of budesonide.

In all $\mathrm{CF}$ and CGD patients with an initial normal ACTH test a retest was performed $\sim 3$ months later. A normal test was obtained in all these patients.

\section{Discussion}

Adrenal insufficiency was found in 11 of $25 \mathrm{CF}$ patients with ABPA treated with a combination of itraconazole and budesonide. Only patients treated with both itraconazole and budesonide showed adrenal insufficiency, whereas none of the patients treated with either itraconazole or budesonide alone were affected. None of the 11 patients with adrenal 
insufficiency had experienced severe disease or other traumas.

The observed suppression of adrenal cortisol synthesis combined with Cushing's syndrome in one of the patients, most likely represents a pharmacological interaction between budesonide and itraconazole. Thus, Cushing's syndrome in this patient may be explained by an increased systemic concentration of budesonide due to inhibition of CYP3A4, and in turn, suppression of pituitary ACTH production leading to adrenal insufficiency. In addition, steroidogenesis in the adrenals may be suppressed by itraconazole [25].

The antifungal activity of azoles is exerted through the binding to and deactivation of the cytochrome P450 mediated enzyme, 14-desmethylase, responsible for converting lanesterol into ergosterol, which is an essential component of the fungal membrane [8, 26]. Ketoconazole is known to produce clinically relevant interactions [27], and is utilised in certain patients to control hypercortisolism of either pituitary or adrenal origin [28, 29]. Though itraconazole is a 10-times less potent inhibitor of CYP3A than ketoconazole in vitro [30], it is a potent inhibitor of the metabolism of various CYP3A4 drugs in vivo, including some synthetic glucocorticoids e.g. dexamethasone and methylprednisolone [17]. Although other azole compounds (itraconazole, fluconazole and miconazole) have a higher affinity to the fungal than the human enzyme system and are assumed to induce less side-effects [26, $27,31]$, these drugs may also compromise the adrenal function when given in high doses and over long periods of time [25].

The very low plasma ACTH levels in all the patients with adrenal insufficiency indicate that reduced metabolism of budesonide may be the primary problem. High levels of plasma-ACTH in response to low plasma-cortisol levels should have been measured if itraconazole had only significantly suppressed steroidogenesis. After itraconazole withdrawal, the tetracosactid-stimulated cortisol level initially only reached subnormal levels. Itraconazole, given its long half-life in plasma (days), specific kinetic properties and high accumulation in various tissues $[32,33]$ may act intracellularly for an extended period of time, which may explain why the suppression of the axis persists for a long period after treatment withdrawal. ACTH production reached normal levels earlier which may reflect decreased serum budesonide and thus, reestablishment of an intact pituitary-adrenal negative feedback mechanism.

Cushing's syndrome has been reported previously in patients treated with orally administered glucocorticoids in combination with itraconazole [34, 35]. Case studies of Cushing's syndrome and adrenal suppression due to treatment with inhaled steroids have also been reported [36, 37]. Thus, daily doses of $800-4,000 \mu \mathrm{g}$ beclomethasone dipropionate (BDP) (mean $1465 \mu \mathrm{g} \cdot \mathrm{day}^{-1}$ ) were reported to cause a moderate and dose-dependent adrenocortical suppression, but as assessed by a low-dose ACTH test, lower BDP or budesonide doses $\left(250-1058 \mu \mathrm{g} \cdot \mathrm{m}^{-2}\right.$, mean $507 \mu \mathrm{g} \cdot \mathrm{m}^{-2}$ ) also appear to impair adrenal function [37-39]. The endogenous cortisol production may decrease by $\sim 20 \%$ in predisposed individuals treated with budesonide in doses of $800 \mu \mathrm{g}$ twice daily [40, 41]. However, the authors have shown previously that budesonide used long-term as an anti-inflammatory agent in doses of $1,600 \mu \mathrm{g}$ daily in CF patients does not suppress adrenal function [14]. Hydrocortisone metabolism may also be impaired, as seen in the patients with Cushingoid symptoms during substitution treatment at standard doses, because the drug is metabolised by the same pathways as budesonide.

The interaction between itraconazole and budesonide, inducing high systemic budesonide levels, may in part explain the reported ability to reduce the glucocorticoid dose $[6,9,10,42,43]$. If this is the case, the use of itraconazole may "spare" the administered dose of steroids but its effect, or side-effects, remain.

Some authors have suggested the possibility of drug-induced Conn's syndrome during itraconazole treatment due to the presence of hypokalemia, oedema and hypertension [25, 44-46]. In the present study normal plasma-renin levels indicate that no involvement of mineralocorticoid secretion was present in any of the patients. Ketoconazole has been associated with a number of gonadal adverse effects, i.e. depression of testosterone synthesis, gynecomastia and impotence [47-49]. However, suppression of gonadal steroids was not observed in any patient in the present study. Itraconazole has been reported to have a greater sensitivity for $11 \beta$-hydroxylase and a relative sparing of the $\mathrm{C} 17-20$ lyase enzyme activity (and androgen activity) [25, 26, 34], which may explain the finding of adrenal but no gonadal suppression.

As clarithromycin, a macrolide antibiotic administered for atypical mycobacteria in patients with $\mathrm{CF}$, has an inhibitory effect on CYP3A and may interfere with the metabolism of budesonide [50-52], some caution is advisable when it is used in combination with itraconazole. Furthermore, a bidirectional interaction between clarithromycin and itraconazole through their effect on CYP $3 \mathrm{~A} 4$ activity may result in increased levels of both [53].

Recent studies have recommended itraconazole as an effective and steroid-sparing treatment of ABPA $[6,9,10,42,43]$. In some patients, worsening of the clinical symptoms of ABPA and an increase in specific IgG subclass antibodies to A. fumigatus resulted in readministration of itraconazole. Suppression of cortisol production was not observed within 2-3 months after re-start of itraconazole treatment in these patients.

Adrenal suppression only seems to be a risk in patients treated with budesonide in combination with itraconazole, yet it did not include all patients on combination therapy despite a similar accumulated dose and duration of treatment. Whether the sideeffects are due to high systemic steroid concentrations, absorption influenced by the degree of inflammation and perfusion, dose and duration of treatment or individual receptor susceptibility is at present unknown. In addition, the amount of CYP3A4 in an individual patient, which varies considerably, may correlate with the magnitude of inhibition and thereby the possible effect of a given inhibitor. Finally, 
concomitant administration of other drugs may induce or inhibit CYP 3A4 activity.

To conclude, care should be taken when itraconazole or other potent CYP3A inhibitors are prescribed concomitantly with steroids including inhaled steroids such as budesonide. The authors recommend that tests for adrenal insufficiency are performed at regular intervals in such patients. In case of adrenal insufficiency, substitution with hydrocortisone needs additional careful monitoring as metabolism of hydrocortisone may also be compromised.

\section{References}

1. Knutsen AP, Slavin RG. Allergic bronchopulmonary mycosis complicating cystic fibrosis. Semin Respir Infect 1992; 7: 179-192.

2. Geller DE, Kaplowitz H, Light MJ, Colin AA. Allergic bronchopulmonary aspergillosis in cystic fibrosis. Reported prevalence, regional distribution, and patient characteristics. Chest 1999; 116: 639-646.

3. Mastella G, Rainisio M, Harms HK, et al. Allergic bronchopulmonary aspergillosis in cystic fibrosis. A European epidemiological study. Epidemiologic Registry of Cystic Fibrosis. Eur Respir J 2000; 16: 464471.

4. Krasnick J, Greenberger PA, Roberts M, Patterson R. Allergic bronchopulmonary aspergillosis: Serologic update for 1995. J Clin Lab Immunol 1995; 46: 137142.

5. Cockrill BA, Hales CA. Allergic bronchopulmonary aspergillosis. Ann Rev Med 1999; 50: 303-316.

6. Leon EF, Craug TJ. Antifungals in the treatment of allergic bronchopulmonary aspergillosis. Ann Allergy Asthma Immunol 1999; 82: 511-517.

7. Lai HC, FitzSimmonds SC, Allen DB, et al. Risk of persistent growth impairment after alternate-day prednisone treatment in children with cystic fibrosis. New Engl J Med 2000; 342: 851-859.

8. Klein NC, Cunha BA. New antifungal drugs for pulmonary mycoses. Chest 1996; 110: 525-532.

9. Nepomuceno IB, Esrig S, Moss RB. Allergic bronchopulmonary aspergillosis in cystic fibrosis: Role of atopy and response to itraconazole. Chest 1999; 115: 364-370.

10. Stevens DA, Schwartz HJ, Moskowitz BL, et al. A randomised trial of itraconazole in allergic bronchopulmonary aspergillosis. New Engl J Med 2000; 342: 756-762.

11. Høiby N. Microbiology of cystic fibrosis. In: Hodson ME, Geddes DM, eds. Cystic Fibrosis. London, Chapman \& Hall, 1995; pp. 75.

12. Koch C, McKenzie SG, Kaplowitz H, et al. International practice patterns by age and severity of lung disease in cystic fibrosis: Data from the epidemiologic registry of cystic fibrosis (ERCF). Pediatr Pulmonol 1997; 24: 147-154.

13. Konstan MW, Butler SM, Schidlow DV, Morgan WJ, Julius JR, Johnson CA. Patterns of medical practice in cystic fibrosis: Part II. Use of therapies. Pediatr Pulmonol 1999; 28: 248-254.

14. Bisgaard H, Pedersen SS, Nielsen KG, et al. Am J Respir Crit Care Med 1997; 156: 1190.

15. Jonsson G, Astrom A, Andersson P. Budesonide is metabolized by cytochrome P450 (CYP3A) enzymes in human liver. Drug Metab Dispos 1995; 23: 137-142.
16. Varis T, Kaukonen K-M, Kivistö KT, Neuvonen PJ. Plasma concentrations and effects of oral methylprednisolone are considerable increased by itraconazole. Clin Pharmacol Ther 1998; 64: 363-368.

17. Varis T, Kivistö KT, Backman JT, Neuvonen PJ. The cytochrome P450 3A4 inhibitor itraconazole markedly increases the plasma concentrations of dexamethason and enhances its adrenalsuppressant effect. Clin Pharmacol Ther 2000; 68: 487-494.

18. Engelhardt D, Weber MM, Miksch T, Abedinpour F, Jaspers C. The influence of ketoconazole on human adrenal steroidogenesis: incubation studies with tissue slices. Clin Endocrinol 1991; 35: 163-168.

19. Engelhardt D, Weber MM. Therapy of Cushing's syndrome with steroid biosynthesis inhibitors. J Steroid Biochem Molec Biol 1994; 49: 261-267.

20. Poulsen K, Jørgensen J. An easy radioimmunological microassay of renin activity, concentration and substrate in human and animal plasma and tissues based on angiotensin I trapping by antibody. J Clin Endocrinol Metab 1974; 39: 816-825.

21. Miller JA, Leckie BJ, Morton JJ, Jordan J, Tree M. A micro assay for active and total renin concentration in human plasma based on antibody trapping. Clinica Chemica Acta 1980; 101: 5-15.

22. Groome NP, Illingworth $\mathrm{PJ}, \mathrm{O}^{\prime}$ Brian $\mathrm{N}$, et al. Detection of dimeric inhibion throughout the human menstrual cycle by two-titre enzyme immunoassay. J Clin Endocrinol Metab 1994; 40: 717-723.

23. Groome NP, Illingworth $\mathrm{PJ}, \mathrm{O}^{\prime}$ Brian $\mathrm{N}$, et al. Measurement of dimeric inhibin B throughout the human menstrual cycle. J Clin Endocrinnol Metab 1996; 81: 1401-1405.

24. Skov M, Pressler T, Jensen HE, Høiby N, Koch C. Specific IgG subclass antibody pattern to Aspergillus fumigatus in patients with cystic fibrosis with allergic bronchopulmonary aspergillosis (ABPA). Thorax 1999; 54: 44-50.

25. Sharkey PK, Rinaldi MG, Dunn JF, Hardin TC, Fetchick RJ, Graybill JR. High dose itraconazole in the treatment of severe mycosis. Antimicrob Agents Chemother 1991; 35: 707-713.

26. Queiroz-Telles F, Purim KS, Boguszewski CL, Afonso FCS, Graf H. Adrenal response to corticotrophin and testosterone during long-term therapy with itraconazole in patients with chromoblastomysis. $J$ Antimicrob Chemother 1997; 40: 899-902.

27. Sonino N, Boscaro M, Paoletta A, Mantero F, Ziliotto D. Ketoconazole treatment in Cushing's syndrome: experience in 34 patients. Clin Endocrinol 1991; 35: 347-352.

28. Loli J, Bercelli E, Tagliaferri M. Use of ketoconazole in the treatment of Cushing's syndrome. $J$ Clin Endocrinol Metab 1986; 63: 1365-1371.

29. Engelhardt D. Steroid biosynthesis inhibitors in Cushing's syndrome. Clin Investig 1994; 72: 481-488.

30. Back DJ, Tjia JF, Abel SM. Azoles, allylamines and drug metabolism. Br J Dermatol 1992; 126: 14-18.

31. Phillips P, Graybill JR, Fetchick R, Dunn JF. Adrenal response to corticotropin during therapy with itraconazole. Antimicrob Agents Chemother 1987; 31: 647649.

32. Grant SM, Clissold SP. Itraconazole. A review of its pharmacodynamic and pharmacokinetic properties, and therapeutic use in superficial systemic mycoses. Drugs 1989; 37: 310-344.

33. Perfect JR, Savani DV, Durack DT. Uptake of 
itraconazole by alveolar macrophages. Antimicrob Agents Chemother 1993; 37: 903-904.

34. Sauty A, Héritier F, Leuenberger Ph, Fitting J-W. Cushing's syndrome in a patient with cystic fibrosis treated with itraconazole and deflacort for allergic bronchopulmonary aspergillosis. Eur Respir J Suppl 1995; 19: 441S.

35. Linthoudt $H$, Van Raemdonck $D$, Demedts $M$, Verleden $G$. The association of itraconazole and methylprednisolone may give rise to important steroid-related side effects. J Heart Lung Transplant 1996; 15: 1165.

36. Wilson AW, Blumsohn A, Jung RT, Lipworth BJ. Asthma and Cushing's syndrome. Chest 2000; 117: 593-594.

37. Kannisto S, Korppi M, Remesk K, Voutilainen R. Adrenal suppression, evaluated by a low dose adrenocorticotropin test, and growth in asthmatic children treated with inhaled steroids. J Clin Endocrinol Metab 2000; 85: 652-657.

38. Prahl O, Andersen GE. Carbohydrate, lipid and glucocorticoid metabolism in children with asthma following treatment with high-dose steroid aerosol. Pediatr Allergy Immunol 1991; 2: 79-82.

39. Broide J, Soferman R, Kivity S, et al. Low-dose adrenocorticotropin test reveals impaired adrenal function in patients taking inhaled corticosteroids. J Clin Endocrinnol Metab 1995; 80: 1243-1246.

40. Derom E, Van Schoor J, Verhaege W, Vincken W, Pauwels R. Systemic effects of inhaled fluticasone propionate and budesonide in adult patients with asthma. Am J Respir Crit Care Med 1999; 160: 157161.

41. Gordon AC, McDonald CF, Thomson SA, Frame $\mathrm{MH}$, Crompton GK. Dose of inhaled budesonide required to produce clinical suppression of plasma cortisol. Eur J Resp Dis 1987; 71: 10-14.

42. Salez F, Brichet A, Desurmont S, Grosbois JM, Wallaert B, Tonnel AB. Effects of itraconazole therapy in allergic bronchopulmonary aspergillosis. Chest 1999; 116: 1665-1668.

43. Germaud P. Allergic bronchopulmonary aspergillosis treated with itraconazole. Chest 1995; 107: 883-883.

44. Ganer A, Arathoon E, Stevens DA. Initial experience in therapy for progressive mycoses with itraconazole, the first clinically studied triazole. Rev Infect Dis 1987; 9: Suppl. 1, S77-S86.

45. Graybill JR, Stevens DA, Galgiani JN, Dismukes WE, Cloud GA. Itraconazole treatment of coccidioidomycosis. Am J Med 1990; 89: 282-290.

46. Tucker RM, Haq Y, Denning DW, Stevens DA. Adverse events associated with itraconazole in 189 patients on chronic therapy. $J$ Antimicrob Chemother 1990; 26: 561-566.

47. Lewis JH, Benson GD, Ishak KG. Hepatic injury associated with ketoconazole therapy: analysis of 33 cases. Gastroenterology 1984; 86: 503-513.

48. Pont A, Williams PL, Loos DS, et al. Ketoconazole blocks adrenal steroid synthesis. Ann Intern Med 1982; 97: 370-372.

49. Sugar AM, Alsip SG, Galgiani JN, et al. Pharmacology and toxicity of high-dose ketoconazole. Antimicrob Agents Chemother 1987; 31: 1874-1878.

50. Furuta T, Ohashi K, Kobayashi K, et al. Effects of clarithromycin on the metabolism of omeprazole in relation to CYP2C19 genotype status in humans. Clin Pharmacol Ther 1999; 66: 265-274.

51. Fost DA, Leung DYM, Martin RJ, Brown EE, Szefler SJ, Spahn JD. Inhibition of methylprednisolone elimination in the presence of clarithromycin therapy. J Allergy Clin Immunol 1999; 103: 1031-1035.

52. Yamano K, Yamamoto K, Kotaki H, et al. Correlation between in vivo and in vitro hepatic uptake of metabolic inhibitors of cytochrome P-450 in rats. Drug Metab Dispos 1999; 27: 1225-1231.

53. Auclair B, Berning SE, Huitt GA, Peloquin CA. Potential interaction between itraconazole and clarithromycin. Pharmocotherapy 1999; 19: 1439-1444. 